\title{
Banco Mundial e política educacional: cooperação ou expansão dos interesses do capital internacional?
}

\section{World Bank and education policy: cooperation or expansion of international capital interests?}

\author{
Rosana Evangelista da Cruz*
}

\begin{abstract}
RESUMO
O atual contexto econômico evidencia uma situação de crise do sistema capitalista, frente ao qual os representantes do interesses do capital internacional, particularmente o Banco Mundial e o FMI, intervêm na organização política e econômica dos países em desenvolvimento, na perspectiva de expandir os interesses dos países hegemônicos por meio de políticas que visam à abertura comercial e financeira, a desregulamentação das relações trabalhistas e a diminuição do tamanho e do papel do Estado na sociedade. Os interesses do capital internacional também permeiam as propostas educacionais propagadas pelo Banco Mundial por meio de acordos intitulados de "cooperação internacional", mais precisamente empréstimos por meio dos quais o banco impõe modelos de políticas e projetos educacionais e normas e regras que condicionam o processo de implementação das parcerias, instituindo uma lógica que favorece a abertura de mercado e a propagação da ideologia neoliberal. O presente artigo aborda o contexto de avanço da intervenção dos organismos internacionais, o histórico do Banco Mundial, a concepção de políticas sociais adotada e a presença efetiva desse organismo nas políticas educacionais, apresentado como exemplos o Projeto Nordeste para a Educação Básica e o Fundo de Desenvolvimento da Escola (Fundescola). Palavras-chave: políticas educacionais, Banco Mundial, Fundescola.
\end{abstract}

* Professora do Departamento de Fundamentos da Educação da Universidade Federal do Piauí. Contato: roecruz@yahoo.com.br 


\begin{abstract}
The current economical context shows up a crisis of the capitalist system, in which the representatives of the interests of the international capital, particularly the World Bank and IMF, intervene on political and economical organization of developing countries, from the central countries perspective of interests expansion through politics that seek commercial and financial opening, absence of labor rules and the weight decrease of State on society. The interests of international capital also permeate education proposals, which are spread by the World Bank through agreements called "international cooperation", more precisely loans which are used by the Bank to impose models of education policy, projects and norms and rules that condition the partnership process implementation and institutes a logic that is favorable to market opening and the propagation of new-liberal ideology. The present article approaches to the context of intervention progresses of International Organisms, the report of the World Bank, the conception of social politics adopted and the effective presence of that organism in the education politics, for example the Northeast Project for the Basic Education and Fund of Development of the School (Fundescola).

Key-words: education politics, World Bank, Fundescola.
\end{abstract}

$\mathrm{O}$ atual contexto mundial apresenta um processo de reestruturação produtiva no qual o desenvolvimento da tecnologia, dos meios de comunicação, da informática e da microeletrônica facilita ao capitalismo o rompimento das fronteiras nacionais (econômicas, políticas, sociais e culturais, entre outras) na perspectiva de expansão dos mercados e superação de sua crise de acumulação, causada pela crescente queda das taxas de lucros. Segundo Gaudêncio Frigotto, a crise do capital "resulta da incapacidade do sistema fazer circular, isto é, fazer consumir produtivamente as mercadorias produzidas", portanto a crise não é conjuntural, "mas um elemento constitutivo, estrutural do capitalismo" (1996a, p. 79-80).

Para o autor, o capitalismo vive um momento de acirramento de uma de suas crises estruturais, buscando superá-la por meio de inúmeras estratégias, para alcançar maiores níveis de acumulação. O processo de globalização econômica, estratégia do capitalismo para a superação da crise, liderado principalmente pelas empresas transnacionais, ${ }^{1}$ acentua a divi-

1 Paulo Nogueira BATISTA JÚNIOR (1998) discute o "mito da empresa transnacional", na medida em que a maioria das empresas internacionais não rompe o vínculo com os interesses de seu país de origem, garantindo a este maior poder de deliberação, mesmo quando as cotas são percentualmente menores em relação ao capital dos demais países. 
são internacional do trabalho, na qual os países mais estruturados economicamente e articulados por meio de organizações, como o Grupo dos Sete (G7), ${ }^{2}$ o Fundo Monetário Internacional (FMI) e o Banco Mundial, garantem a preponderância dos interesses de alguns países sobre os demais, que têm de submeter-se às diretrizes econômicas impostas, mesmo em detrimento de seus interesses nacionais, interferindo inclusive na possibilidade de autodeterminação, de soberania.

Vários autores têm questionado a globalização econômica, e, neste trabalho, destacam-se as contribuições de LEHER (1998) e BATISTA JÚNIOR (1998), que colaboram para desmistificar as tendências que consideram o processo de globalização um movimento inevitável de inserção dos países na "nova economia global", fortalecendo as perspectivas que defendem a sua mundialização. Assim, a globalização é tratada por esses autores, não como um movimento ou um conceito, mas como uma ideologia que contribui "para obstruir o debate sobre a política econômica e social e para dificultar a identificação dos erros das autoridades governamentais" (BATISTA JÚNIOR, 1998, p. 10).

Neste sentido, Batista Júnior denuncia que no Brasil, a partir do governo Fernando Collor de Mello, ocorreu a adoção de um conjunto de políticas que submeteu a "economia nacional de forma repentina à competição internacional” (1998, p. 10). As conseqüências dessa abertura são vividas nas dimensões econômicas e sociais, a exemplo de elevadas taxas de juros, desnacionalização da economia, falência de pequenas empresas, aumento do desemprego e do subemprego, que representam conseqüências das políticas governamentais, mesmo que dissimuladas sob o termo "globalização".

Segundo Leher, não existe uma real proposição no sentido de abolir totalmente as fronteiras nacionais, uma vez que, se por um lado existe constante pressão dos grupos econômicos dominantes para flexibilização das barreiras econômicas e comerciais, por outro existe uma manutenção de impermeáveis barreiras protecionistas nas economias dos países que compõem esses grupos, mantendo-se cinco monopólios chaves: tecnológico, de controle do fluxo financeiro de envergadura mundial, de acesso aos recursos naturais do planeta, de comunicação e armamentos de destruição massiva (1998, p. 33).

2 Compõem o G7: Estados Unidos, Japão, França, Alemanha, Reino Unido, Itália e Canadá. 
A ideologia da globalização é caracterizada pelo autor como um esforço do capital para impedir a compreensão de que os problemas estruturais do capitalismo são frutos das contradições desse mesmo sistema, da crise estrutural iniciada na década de 70 , difundindo a ideologia da globalização como pensamento único. Nesta ideologia, além da defesa da livre circulação de mercadorias e de capital, procura-se convencer a sociedade de que existe menor cisão entre as classes já que a posição de cada um passaria a ser determinada pelo capital educacional, atenuando a intensa divisão socioeconômica existente.

Esse entendimento sobre a ideologia da globalização é reiterado por Milton Santos, pois, segundo ele, "essa ideologia não caiu do céu. Foi construída. Houve uma preparação prévia para a chamada globalização, com produção de idéias encomendadas à inteligência das grandes empresas, com suas fundações, e as universidades hegemônicas comandaram a pesquisa e a formulação dessas idéias, alocando, em grande escala, os recursos necessários para isso" (2000, p. 29).

Neste processo de reorganização produtiva e de propagação da ideologia da globalização, segundo SILVA (1999), o Banco Mundial assume o papel de centro de poder internacional que, articulado ao FMI, impõe aos países em desenvolvimento um programa de ajuste estrutural conveniente aos interesses do grande capital, atuando no sentido de monitorar e aplicar sanções econômicas àqueles países que não se ajustem às suas orientações, consideradas necessárias ao crescimento econômico e à estabilidade sociopolítica.

As proposições neoliberais, segundo NEGRÃo (1996), foram explicitadas no Consenso de Washington, fruto de uma reunião, ocorrida em 1989, envolvendo o governo dos EUA, técnicos do Banco Mundial, do FMI e do BID e economistas de perfil liberal, com o objetivo de debater as reformas econômicas que deveriam ser adotadas pelos países da América Latina.

As principais orientações neoliberais referem-se ao questionamento do papel do Estado na sociedade e na economia, propondo diminuir sua interferência sobre estes setores. Os três principais pilares da reestruturação proposta baseiam-se na diminuição do papel e tamanho do Estado na sociedade (privatizações, demissões e desvio de reivindicações populares para a esfera do mercado), desregulamentação das relações trabalhistas (quebra da estabilidade, criação de contratos temporários, terceirizações, diminuição da carga tributária sobre o capital) e abertura econômica e comercial 
(possibilitando ao capital internacional o investimento direto nos países conforme seus interesses e necessidades de expansão) (NEGRÃO, 1996).

As reformas expressas no Consenso de Washington espelham a retomada dos pressupostos liberais e das propostas debatidas por Friedrich August von Hayek em sua obra $O$ caminho da servidão, publicada em 1944, em oposição às políticas do "Estado do Bem-Estar Social" difundidas no pós-Segunda Guerra Mundial, sob o argumento de que todo tipo de intervenção estatal, além de ser um atentado às liberdades individuais, seria uma aproximação aos regimes totalitários e comunistas.

O "Estado do Bem-Estar Social" foi uma forma de regulação social caracterizada pela "emergência de uma intensa e progressiva intervenção planejada na economia para evitar a fúria da desordem produzida pelo mercado", quando o Estado passou a controlar áreas estratégicas da economia (energia, telecomunicações, petróleo, minérios), assumindo, em algumas situações, o papel de produtor direto, além de subsidiar certos setores e responder, por meio de políticas sociais, demandas da classe trabalhadora organizada em sindicatos (FRIGOTTO, 1996a, p. 81).

Para PERONI (1999), atualmente o capitalismo vive uma crise estrutural e utiliza-se do neoliberalismo como estratégia política e ideológica para superá-la. O neoliberalismo resgata os princípios liberais, propondo um Estado forte o suficiente para apoiar o crescimento e desenvolvimento do capital, e mínimo quanto às políticas sociais, configurando um processo no qual as conquistas históricas da classe trabalhadora são substituídas por políticas precárias ou mesmo eliminadas.

A diferença entre liberais e neoliberais refere-se ao fato de que os últimos distanciam-se de seus mentores originais, como Adam Smith e Stuart Mill, ao defenderem que serviços sociais básicos e funções de segurança pública também sejam transferidos para a esfera privada, para a dinâmica do mercado, a exemplo da defesa da privatização de serviços nas áreas de saúde, educação, previdência social e serviço penitenciário (SILVA, 1999, p. 33).

A reforma proposta ocasiona sérios problemas sociais nos países onde está sendo implementada: desemprego; subemprego; precarização das condições de trabalho, redução de salários, desregulamentação dos direitos trabalhistas e previdenciários; entre outros problemas, agravados pelo desemprego estrutural, fruto do acelerado avanço tecnológico.

Com a justificativa de contribuir para o desenvolvimento e criar políticas para combater os problemas socioeconômicos, a título de "coopera- 
ção internacional”, segundo FONSECA (1998), são realizadas inúmeras operações financeiras, nas quais organismos internacionais viabilizam "empréstimos" para os países em desenvolvimento com cláusulas que, muitas vezes, superam os juros aplicados no mercado, prevendo duras sanções (multas, suspensão de repasses, entre outras), caso o país "beneficiado" não tenha condições de cumprir os acordos e metas estabelecidos.

Nessa perspectiva, criam-se os Programas de Ajuste Estrutural, um tipo de financiamento não mais vinculado a projetos, mas a condicionalidades de cunho macroeconômico, reformas e metas acompanhadas diretamente pelo Banco Mundial e FMI. Assim, para a liberação de empréstimo por uma das agências, a outra dá o aval como um tipo de condicionalidade cruzada, portanto, submetendo a decisão de negociações das dívidas externas e a liberação de novos empréstimos a um pretenso cumprimento de metas de saneamento dos gastos públicos (FONSECA, 1998).

Assim, conforme memorando do presidente do Banco Mundial sobre o Country Assistence Strategy (CAS), documento oficial que definiu a estratégia do Banco Mundial para o Brasil em 1997: "a equipe do banco e o FMI trabalham em estreita cooperação no monitoramento do desenvolvimento econômico e na formulação de aconselhamento político" (BANCO MUNDIAL, 1997, p. 53). ${ }^{3}$ Este depoimento evidencia a pertinência da crítica realizada por vários autores referente à articulação entre Banco Mundial e FMI para garantir que os países implementem políticas mais convenientes aos interesses do capital.

Segundo Francis Mary Guimarães Nogueira, o Banco Mundial, ao captar recursos junto a bancos privados internacionais para viabilizar a modalidade de empréstimo para ajustes estruturais ou setoriais, assume, também, a tarefa de definir as normas operativas desses empréstimos. Assim, tais empréstimos passaram a ser concedidos de forma a forçar que os países aceitassem quatro pontos básicos do acordo, todos permeados por ações voltadas à abertura da economia:

1) Implantar uma política comercial e de preços, na direção de liberalizar o comércio, como forma de rever as distorções econômicas ocorridas no

3 Documento disponível no livro Estratégia dos Bancos Multilaterais para o Brasil: uma análise crítica de documentos inéditos, organizado por Aurélio VIANNA JÚNIOR (1998). 
passado, tornando eficaz o setor industrial desses países desenvolvidos, e garantindo a exportação dos excedentes produtivos; 2) rever a política de investimento público, para que o Estado redirecionasse suas prioridades em "função do andamento da estrutura de preços internacionais e dos recursos disponíveis"; 3 ) reorientar a política orçamentária, reduzindo o máximo do déficit fiscal, e atendendo ao máximo as atividades produtivas privadas; e, por último, 4) promover reformas institucionais para garantir maior eficácia ao setor público e às empresas (NOGUEIRA, 1999, p. 126).

Os empréstimos para ajustes setoriais foram introduzidos em 1983, como uma modalidade focalizada em setores específicos da economia, não direcionados aos ajustes estruturais, entretanto servindo de suporte a estes.

\section{Banco Mundial: um breve histórico}

O Banco Mundial foi fundado na Conferência Monetária e Financeira das Nações Unidas, conhecida como Conferência de Bretton Woods, realizada em 1944 nos Estados Unidos, quando 44 países se reuniram com o objetivo de traçar estratégias que pudessem colaborar para a reconstrução dos países europeus no pós-Segunda Guerra Mundial, com vistas a garantir sua estabilidade e crescimento econômico (SILVA, 1999).

O objetivo inicial do Banco Mundial restringia-se à concessão de empréstimos não comerciais a longo prazo, com vistas à reconstrução no pós-guerra das economias arrasadas. Entretanto, a partir de 1950, com a mudança no cenário internacional e a iminência da Guerra Fria, o banco passa a oferecer, segundo Maria Clara Couto Soares, “....assistência econômica, política e militar para os países do terceiro mundo...", na perspectiva de garantir a integração e o fortalecimento do Bloco Capitalista, fornecendo empréstimos para os setores de energia, telecomunicação e transporte (1998, p. 18).

Em 1968, quando Robert MacNamara, secretário de Defesa do EUA entre 1961 e 1968, assume a presidência do Banco Mundial, gestão que vigorou entre 1968 e 1981 (SILVA, 1999, p. 95-97), inicia-se uma fase de 
preocupação com a pobreza, porém pautada na concepção de que o crescimento econômico garantiria automaticamente a melhoria da qualidade de vida dos indivíduos. Neste período, o setor da agricultura e os setores sociais passaram a ser contemplados com a maior parte dos empréstimos oferecidos.

Segundo Samuel Lichtensztejn e Mônica Bauer, "MacNamara não dirigiu o Banco Mundial com a mentalidade própria de um banqueiro, mas com a de um estrategista internacional que pretendia conseguir na paz o que não pôde conquistar na guerra: reconhecer reivindicações populares e controlá-las, em um período do capitalismo industrial e da hegemonia norte-americana" (1987, p. 183).

Na década de 70, com o acelerado processo de globalização da economia, as teorias monetaristas neoliberais passam a influenciar as economias, alcançando hegemonia nas décadas seguintes. Neste período, o Banco Mundial e o FMI passam a oferecer aparato ideológico e político para a expansão do neoliberalismo em escala mundial.

Essas instituições responsabilizam-se pelo monitoramento do pagamento das dívidas externas, assumindo o papel estratégico na reestruturação econômica dos países em desenvolvimento, garantindo a implantação de políticas de reajuste econômico e defendendo os interesses dos grandes credores internacionais.

Tal papel é explicitado na década de 80, quando o Banco Mundial passa a responsabilizar-se pelo fornecimento de aval para fontes de crédito internacional, por meio das condicionalidades, que vinculam os empréstimos e negociações à adequação das estruturas econômicas dos países devedores ao modelo neoliberal.

Por isso as "reformas profundas em suas instituições são consideradas mais importantes do que o alívio da dívida", visto que a prioridade refere-se aos interesses e necessidades de expansão do capital internacional (SOARES, 1998, p. 23). Tal fato pode ser ilustrado pelo considerável aumento das dívidas externas dos países da América Latina nas décadas de 80 e 90: segundo dados de Marcos Arruda, houve um aumento de US\$ 390 bilhões de dólares, em 1985, para US\$ 657 bilhões de dólares, em 1996, apesar do pagamento ininterrupto de altos encargos durante esses 12 anos. No caso do Brasil, em 1985 a dívida externa era de US\$ 105 bilhões de dólares e, mesmo tendo pagado US\$ 282 bilhões de juros e amortizações 
entre 1985 e 1998 (126 bilhões só de juros), em 1998 a dívida aumentara para US\$ 230 bilhões de dólares (1999, p. 12). ${ }^{4}$

$\mathrm{O}$ aumento desenfreado da dívida externa inicia-se, ainda, durante a ditadura militar, no contexto de empréstimos a juros baixos como estratégia de estimular os países em desenvolvimento a contraírem mais dívidas junto aos credores internacionais. Um exemplo desta situação é o fato de a dívida externa brasileira ter crescido 42 vezes, de US\$ 2,5 bilhões a US\$ 105 bilhões de dólares entre os anos de 1964 e 1985. Entretanto, a situação determinante para o agravamento do problema da dívida ocorreu, entre os anos de 1979 e 1981, devido ao acelerado aumento da taxa de juros, que subiu de $6,25 \%$ para $24 \%$, medida adotada unilateralmente pelos EUA, penalizando todos os países que tinham suas dívidas em dólares, mergulhando-os na crise (ARRUDA, 1999, p. 12).

A conhecida crise da dívida externa de 1982 motivou o Banco Mundial e o FMI a aumentarem os empréstimos para os países da América Latina, tornando-os, segundo LEHER (1998), reféns destas instituições, facilitando a inserção de condicionalidades no processo de implementação das políticas de ajuste estrutural. Assim, a crise e a emergência dos países de $3^{\circ}$ Mundo em conseguir empréstimos rápidos e vultuosos, para o equilíbrio do sistema financeiro, levaram-nos a aceitar sem resistências as propostas de reformas na economia, inclusos os empréstimos de ajuste estrutural, conforme orientações do Banco Mundial.

É importante destacar, conforme citado anteriormente, que a eficácia nas ações do banco no processo de implementação das políticas neoliberais não decorre apenas de seus empréstimos de ajuste estrutural, mas também de sua atuação enquanto catalisador de empréstimos externos, na medida em que fornece o aval àqueles países comprometidos com as reformas para que executem a negociação com o capital privado internacional, tornando-os, assim, dependentes dessas instituições (LEHER, 1998, p. 137).

Ao analisar os 50 anos de atuação do Banco Mundial, SOARES (1998) aponta uma performance bastante negativa, visto o crescimento patrocinado ser desigual e perverso socialmente, contribuindo para o aumento da

4 Segundo Arruda, na relação de empréstimos internacionais para o Brasil existem três categorias de credores: os credores oficiais (países mais ricos, principalmente EUA, Japão, Alemanha, França, Inglaterra, Suíça, Canadá e Holanda); os credores privados (bancos privados internacionais) e os credores multilaterais (Banco Mundial, FMI e BID) (1999, p. 15). 
concentração de renda e a ampliação da pobreza e exclusão social em escala mundial.

O impacto negativo das políticas do Banco Mundial deflagrou, na década de 90, pressões de organizações não-governamentais (ONGs) e parlamentares no sentido de reformulação de suas propostas. Na tentativa de “... construir novas bases de legitimidade, atenuando as críticas aos programas de ajuste estrutural e as evidências dos efeitos nefastos de tais políticas", o Banco Mundial tem adotado novos programas e procedimentos. Dentre eles, vale destacar o Painel Independente de Apelação, ou Painel de Inspeção, criado em 1993, instância pela qual as entidades e cidadãos que se sintam prejudicados pela implementação de programas do Banco Mundial podem requerer uma inspeção, que será efetivada para, se for o caso, sua readequação (SOARES, 1998, p. 26).

O Painel de Inspeção é um comitê do Banco Mundial que recebe as reclamações sem que elas necessitem de aprovação prévia dos governos nacionais. Tais demandas são investigadas por uma comissão, composta por três especialistas e dois secretários, que encaminha um parecer com recomendação à reunião de diretores executivos do Banco Mundial, formado por representantes dos governos dos países membros, para votação e encaminhamentos (VIANNA JÚNIOR, 1998, p. 191). O limite deste instrumento está no próprio procedimento, uma vez que os diretores executivos dos diferentes países têm voto proporcional à sua participação acionária no banco, ou seja, em última instância decidem os países capitalistas mais desenvolvidos do planeta, os componentes do G7. Mesmo assim, o autor indica a possibilidade de ocorrerem algumas situações em que os países não pertencentes a este grupo convirjam seus votos fazendo valer alguma recomendação realizada pela equipe do painel. ${ }^{5}$

Entretanto, qualquer proposta de democratização dos projetos do Banco Mundial esbarra em sua estrutura antidemocrática, sem transparência, ou

5 No Brasil, até 1998, foram encaminhadas três solicitações para investigação de projetos financiados pelo Banco Mundial. Duas referem-se aos projetos Planafloro (Rondônia, 1995) e Itaparica (Pernambuco e Bahia, 1997). O primeiro resultou em reformulação do Projeto e acompanhamento pelo Painel de Inspeção; o segundo na aprovação de um Plano de Ação para solucionar questões pendentes do Projeto. A inspeção no terceiro projeto foi solicitada em 1998 e referia-se ao Programa "Cédula da Terra", do Instituto Nacional de Colonização e Reforma Agrária (INCRA), tendo sido negado (VIANNA JÚNIOR, 1999, p. 5354). 
na impossibilidade de participação da sociedade. As ONGs do mundo inteiro pressionam para que ocorra a democratização do sistema de decisão, das ações e da prestação de contas do Banco Mundial, de forma a garantir a participação da sociedade civil, conforme enunciado a seguir:

\begin{abstract}
Na base dessas pressões está a noção de que os fundos dessas instituições são de natureza pública, pois procedem - direta ou indiretamente - dos contribuintes dos países membros, geram um endividamento que onera a sociedade como um todo e são geralmente aplicados em programas e projetos que incidem sobre populações e nações inteiras (ARRUDA, 1998, p. 54).
\end{abstract}

Apesar de os recursos do Banco Mundial serem provenientes dos países associados, o banco está fora dos controles previstos na estrutura do aparelho do Estado, excluindo a sociedade civil que não tem acesso sequer às informações sobre os financiamentos deste organismo internacional.

O Banco Mundial, segundo KRUPPA (2000), tem como principais fontes de recursos o mercado financeiro, empréstimos e contribuições dos países membros. Podem pleitear empréstimos do banco governos, estados e empresas privadas, porém todos devem ter a garantia dos governos soberanos. Atualmente, o Grupo Banco Mundial conta com 181 países membros e com uma junta de governadores, composta pelos ministros da Fazenda de todos os países membros; com uma diretoria executiva composta por 24 membros que representa todos os países; um presidente, três diretores-gerentes e 24 vice-presidentes (BANCO MUNDIAL, 1999). ${ }^{6}$

A diretoria executiva é composta conforme o peso dos votos de cada país participante, assim, como o peso do voto é determinado pela participação acionária no banco, os EUA (16,53\%), Japão (7,93\%), Alemanha (4,52\%), França (4,34\%) e Reino Unido (4,34\%) detêm cerca de $40 \%$ dos votos (BANCO MUNDIAL, 1999).

Pesquisa realizada em 1996 revela que 143 países membros do Banco Mundial tinham até " $0,5 \%$ de poder de voto; 16 países de 0,5 a $0,99 \%$ de

6 O mundo atual conta com 192 países ao todo, ou seja, apenas 11 países do planeta não são sócios participantes do Banco Mundial (KRUPPA, 2000). 
poder de voto; 6 de 1,0 a 1,62\%; 10 de 1,63 a 3,0\%; 4 de 3,01 a $6,10 \%$ e apenas 1, os EUA, 17,2\%". Entretanto, segundo Vianna Júnior, apesar de o Brasil não ser do grupo dos controladores majoritários do Banco Mundial, tem um poder considerável dentro do grupo dos minoritários, já que em 1996 detinha 1,63\% dos votos, ocupando o $15^{\circ}$ lugar na lista dos países com maior poder de voto no BANCO MUNDIAL (1999, p. 44).

Entretanto, o mesmo autor revela que "os representantes do governo brasileiro fazem coro com os que não querem instrumentos de transparência e participação no FMI, no Banco Mundial e no BID, sendo que, muitas vezes, votam com os interesses hegemônicos do Banco Mundial", em detrimento dos interesses dos demais países filiados (VIANNA JÚNIOR, 1998, p. 2-3).

A distribuição das cotas revela que os Estados Unidos exercem grande influência na gestão do Banco Mundial desde a criação, pois seus estatutos estabelecem que o peso de voto é proporcional à participação de capital, além disto, segundo Lichtensztejn e Bauer, durante a Conferência de Bretton Woods foi definido que o cargo de presidente do Banco Mundial ficaria sempre com um norte-americano e o de diretor gerente do FMI com um europeu (1987, p. 159).

Para concluir, a citação de Arruda bem ilustra o espírito do trabalho desenvolvido pelo Banco Mundial:

Resumindo, o Banco Mundial é uma instituição paradoxal. Seus recursos, a natureza dos seus objetivos e o alcance de sua ação são de caráter essencialmente público, mas sua prática é predominantemente a de um banco comercial privado. Sua lealdade nominal é ao conjunto dos países membros, mas (...) suas políticas coincidem principalmente com os interesses dos governos e das elites do mundo industrializado, sobretudo dos EUA (ARRUDA, 1998, p. 70). 


\section{Política social na perspectiva do Banco Mundial}

Ao analisar a perspectiva de política social adotada pelo Banco Mundial, observa-se a filiação desta à concepção liberal, mais especificamente neoliberal, uma vez que, conforme visto anteriormente, a última remete à esfera do mercado até os serviços mais essenciais da sociedade, como saúde, segurança e educação. A proposta de política social do banco é, eminentemente, compensatória e paliativa, tendo por objetivo a manutenção e ampliação do modo de produção capitalista, pois aponta que os problemas sociais são fruto do precário crescimento social, político e econômico dos países em desenvolvimento.

O Banco Mundial propaga um modelo de desenvolvimento que visa à contenção demográfica por meio de políticas compensatórias de alívio da pobreza. Em nenhum momento, as causas estruturais da questão social são consideradas, não se apresenta uma discussão sobre o problema da distribuição de renda no país como um elemento gerador da miséria, assim como não se pressupõe um projeto para eliminar as desigualdades sociais, necessárias e intrínsecas ao modo de produção capitalista.

Francisco de Oliveira aponta o papel dual das políticas sociais, pois, se por um lado, elas colaboram para a diminuição dos conflitos sociais, por outro atuam diretamente na reprodução da força de trabalho, suprindo os elementos que deveriam ser garantidos pelo salário do trabalhador. $\mathrm{O}$ autor indica a existência de pesquisas que evidenciam que o salário indireto possibilitado pelas políticas sociais chega a compor $45 \%$ do salário direto do trabalhador (1998, p. 22).

Oliveira argumenta, também, historicamente de que modo o padrão de financiamento público tem contribuído para a acumulação do capital, pois os recursos públicos investidos em gastos sociais são revertidos diretamente ao interesse capitalista, seja pela garantia da reprodução da força de trabalho, seja por outros investimentos diretos na infra-estrutura necessária à manutenção e ampliação do capital. Além disso, o próprio autor lembra que o Estado atua como comprador permanente de serviços e mercadorias e conclui, ainda, que os recursos públicos são indispensáveis ao acúmulo de capital, daí a disputa permanente para a manutenção do controle dos aparelhos do Estado. 
O próprio Banco Mundial reconhece a importância de o Estado manter suas funções mínimas, porém sem exclusividade, pois "Os Estados devem complementar os mercados, e não substituí-los" (BANCO MUNDIAL, 1997, p. 18). É nesta perspectiva que o banco esclarece sua posição sobre o papel do Estado em relação às políticas sociais:

Embora o Estado ainda tenha um papel central na provisão e garantia de serviços básicos - educação, saúde e infra-estrutura - não é óbvio que deva ser o único provedor, ou mesmo que seja provedor. As decisões do Estado em relação à provisão, financiamento e regulamentação desses serviços devem basear-se nas vantagens relativas dos mercados, da sociedade civil e dos órgãos do governo (BANCO MUNDIAL, 1997, p. 28).

O pronunciamento do presidente do Banco Mundial evidencia o papel estratégico das políticas sociais na manutenção da ordem capitalista:

Quando os privilegiados são poucos e os desesperadamente pobres são muitos e quando a diferença entre ambos os grupos se aprofunda em vez de diminuir, só é questão de tempo até que seja preciso escolher entre os custos políticos de uma reforma e os riscos políticos de uma rebelião. Por este motivo, a aplicação de políticas especificamente encaminhadas para reduzir a miséria dos $40 \%$ mais pobres da população dos países em desenvolvimento é aconselhável não somente como questão de princípio, mas também por prudência. A justiça social não é simplesmente uma obrigação moral, é também um imperativo político (MAC'NAMARA, apud FONSECA, 2000, p. 1). ${ }^{7}$

Conforme a fase do conflito entre o capital e o trabalho, parece ser mais segura, ou vantajosa, a incorporação de parcela das reivindicações dos trabalhadores, justamente como estratégia para a manutenção da situação de classe.

7 MAC'NAMARA, R. S. Equidade social y crecimiento económico. México: El Mercado de Valores, out. 1972. n. 41, p. 1064-1072. 
A crescente precarização das políticas sociais revela o fortalecimento da concepção de Estado mínimo, segundo a qual ele deixa de promover políticas sociais básicas, transferindo a responsabilidade para a própria sociedade, dada a suposta incapacidade deste Estado de responder a todas as demandas sociais:

A mensagem é que o Estado pode ficar à altura dos desafios que enfrenta, mas isso somente se, primeiro, ajustar o que procura fazer ao que é capaz de fazer, e, depois, aumentar o número de coisas que pode fazer com habilidade, mediante o fortalecimento das instituições públicas (BANCO MUNDIAL, 1997, p. 19).

Assim, seria necessário, primeiramente, um ajuste fiscal e o saneamento do déficit público, com restrição ou diminuição das funções do Estado à sua capacidade, o que poderia ser feito por meio do repasse de demandas para a iniciativa privada, para a esfera do mercado.

Nesse sentido, segundo CORAGGIO (1998), as políticas sociais públicas seriam destinadas exclusivamente aos mais pobres, ou seja, àqueles que se localizam abaixo da linha de pobreza e indigência, ${ }^{8}$ por meio de um pacote de políticas sociais públicas básicas; entretanto, aquele que tivesse interesse em serviço complementar, não básico, pagaria por ele. Esta perspectiva reforça a segmentação social da população, visto que propõe um serviço social público de baixa qualidade aos pobres e o acesso a um serviço privado de melhor qualidade àqueles que têm condições de pagar.

Nas políticas sociais, localiza-se, também, a ingerência do Banco Mundial na soberania dos países, visto que, além de impor condicionalidades ao crédito e ao comércio, indica prioridades para as políticas sociais, sempre na perspectiva de que elas subsidiem o aumento da competitividade no interior da sociedade, prioritariamente por intermédio do investimento em capital humano, relacionado à propagação de capacidades básicas para o mundo do trabalho (CORAGGIO, 1998).

8 O Banco Mundial define como pobreza rendas per capita inferiores a US\$ 30 por mês, ou um dólar por dia. A situação de indigência é imputada às rendas familiares correspondentes, no máximo, ao valor de aquisição de uma cesta básica de alimentos que atendam os requerimentos nutricionais recomendados pela FAO/OMS/ONU, para a família como um todo. 
A Teoria do Capital Humano foi desenvolvida principalmente por Theodore Schultz nos EUA, década de 50, em pesquisa que tinha por objetivo descobrir o fator que determina a diferença entre desenvolvimento e subdesenvolvimento entre os países. A pesquisa concluiu que a chave desta diferença é o fator educação, pois ela propicia a potencialização da capacidade produtiva dos indivíduos e países, sendo fator determinante para o desenvolvimento das nações e para a mobilidade individual. Esta pesquisa, apesar de ter rendido para seu coordenador o prêmio Nobel de Economia, é bastante conveniente aos interesses do capital, sendo que suas bases científicas são questionadas por inúmeros pesquisadores (FRIGOTTO, 1996b, p. 41), pois a mesma é uma estratégia de difundir um novo senso comum que impeça os trabalhadores de visualizarem as contradições do sistema capitalista e de se rebelarem contra ele.

\section{O Banco Mundial e as políticas educacionais}

No campo educacional, o discurso neoliberal resgata e reformula os enfoques economicistas da Teoria do Capital Humano, apontando a relação de dependência entre educação e desenvolvimento econômico e social, excluindo os fatores estruturais que determinam as diferenças de classe e enfatizando o valor do desempenho individual como determinante da condição de cada um na sociedade: "a educação pode ajudar a reduzir a desigualdade, proporciona novas oportunidades aos pobres e, conseqüentemente, aumenta a mobilidade social" (BANCO MUNDIAL, 1995, p. xviii).

Ao analisar esta perspectiva, GENTILI (1996) indica que o neoliberalismo propõe a transferência da lógica do mercado para a educação, elege a livre concorrência como fundamental para a garantia da eficiência e da qualidade dos serviços educacionais prestados e transfere a meritocracia vigente no campo empresarial para o educacional, pois assim estaria garantindo o estabelecimento de critérios competitivos, adequados para promover os mais capazes e esforçados.

Desse modo, para o autor, o Banco Mundial apresenta como estratégia para melhorar o acesso, a eqüidade e a qualidade dos sistemas escolares 
um pacote de medidas que envolve uma determinada ideologia e orientação reformista, que, na verdade, indica o descompromisso com o objetivo de elevar a qualidade de ensino, visto que impõe a redução dos gastos públicos com educação.

As propostas evidenciam que se procura descentralizar determinadas ações, particularmente aquelas referentes às responsabilidades financeiras com a manutenção das escolas e a gestão, tendo em vista a municipalização. A descentralização proposta caracteriza-se mais como uma desconcentração, visto que o governo federal deve centralizar as grandes diretrizes educacionais, a elaboração do currículo, a política de avaliação e de formação de educadores, ficando as demais esferas do sistema apenas com a execução das ações dentro de parâmetros previamente definidos (GENTILI, 1996).

Juan Casassus expõe que as propostas de desconcentração refletem "processos cujo objetivo é assegurar a eficiência do poder central", enquanto a descentralização "é um processo que visa assegurar o poder local". Assim, ao analisar as diferentes experiências de descentralização em curso na América Latina, indica que, com raras exceções, praticamente todas refletem processos de desconcentração (1990, p. 17).

Para o autor, a desconcentração é um movimento de cima para baixo, enquanto a descentralização é de baixo para cima. A análise mostra-se pertinente, visto que, em geral, as propostas para a gestão educacional desenvolvidas no decorrer da década de 90 foram motivadas pelo poder central, normalmente sem um processo de consulta às demais esferas do sistema.

O Banco Mundial afirma a necessidade de envolver pais e comunidade nos assuntos escolares, inclusive com a possibilidade de contribuição econômica para a sustentação da infra-estrutura, e parcerias com setor privado e ONGs. Além disso, quanto às orientações referentes ao financiamento da educação, sugere que as despesas sejam compartilhadas com as comunidades locais, por meio da inserção de cobranças de taxas para o ensino superior e o estabelecimento de empréstimos educativos para alunos carentes, que poderão reembolsar posteriormente os gastos realizados com educação (BANCO MUNDIAL, 1995).

A questão da autonomia toma corpo e propaga-se como proposta progressista para a educação escolar; entretanto, vale discutir que a autonomia concebida pelo Banco Mundial e pelos Ministérios de Educação comprometidos com a implementação das políticas de diminuição do papel do Estado, refere-se a mais uma perspectiva de desresponsabilização do Esta- 
do com a escola, envolvendo a comunidade na gestão educacional e na manutenção financeira das escolas, além da instituição de regimes precários de trabalho e da possibilidade de escolas contratarem e demitirem profissionais da educação, quebrando a unidade e organização sindicais.

Em geral, o Banco Mundial procura respaldar-se em argumentos pretensamente técnicos para poder justificar suas políticas e propostas, envolvendo-as com uma aura de cientificidade, mas que na realidade terminam por revelar seu compromisso de imprimir uma lógica mercadológica ao sistema educacional.

Para o Banco Mundial, a crise do Estado e da educação em particular, só pode ser superada quando tiver ajustado seu papel, no sentido de revigorar sua capacidade institucional por meio de regras, parcerias e pressões competitivas dentro e fora do Estado. É neste sentido que a implementação de um sistema de avaliação visa a criar uma competição interna no processo de divisão dos insumos, elevando o esforço para melhor desempenho das diferentes instituições no uso de recursos públicos (BANCO MUNDIAL, 1997).

O Banco Mundial sugere, dentre as estratégias para superação da crise educacional, parcerias com a iniciativa privada, dada a experiência administrativa considerada exitosa e a possibilidade de colaborar para o estabelecimento de um novo padrão de gestão.

Assim, a transferência da lógica do mercado para as relações educacionais remete ao entendimento da escola como empresa, dos alunos e pais enquanto consumidores e da aprendizagem como produto, relegando os demais aspectos da realidade educacional (CORAGGIO, 1998, p. 102).

O Banco Mundial traça uma proposta educacional voltada aos interesses e necessidades do mercado de trabalho; daí a ênfase no ensino fundamental como fator relevante de retorno para o crescimento econômico do país, para melhoria da qualidade de vida e para a redução da pobreza. Entretanto, o Banco Mundial aponta que a demanda de educação no contexto de economia globalizada deve ser a formação que possibilite ao trabalhador o desenvolvimento da capacidade de aprender, para que este possa se adequar com facilidade às aceleradas transformações do mundo do trabalho.

A prioridade para o ensino fundamental é uma questão colocada muito claramente pelo Banco Mundial, fato bastante criticado por autores como LEHER (1998), pois ele nota um "apartheid educacional", uma vez que esta "orientação" dada aos países em desenvolvimento difere claramente das orientações executadas pelos países desenvolvidos, que têm investido historicamente no desenvolvimento do ensino superior e em pesquisas de ponta. 
Segundo o autor, o banco conseguiu que todos os países em desenvolvimento adotassem esta agenda, fato que contribui para a manutenção da dependência tecnológica dos países em desenvolvimento em relação aos países do primeiro mundo.

As propostas do Banco Mundial visam também a uma política de contenção demográfica e ao alívio das tensões sociais provocadas pelas políticas que ele financia em favor do crescimento e desenvolvimento do capital, sendo a educação, conforme LEHER (1998, p. 9-84), um requisito para a globalização, pois cumpre uma função ideológica ao responder às necessidades do capitalismo de operar as contradições do sistema, fruto de sua crise estrutural, respondendo, portanto, às necessidades do capital.

Segundo a concepção adotada por Leher, a ideologia é uma realidade objetiva e operante, que de fato tem o poder de mover as ações dos governos no sentido de obscurecer a exclusão estrutural do sistema. Assim, a educação é uma "condição necessária para a reprodução econômica e ideológica do capital", visto que, por um lado, alivia a pobreza causada pelas políticas de ajuste estrutural e, por outro, promove a ideologia da globalização, evitando contestações à ordem, uma vez que o indivíduo interioriza a culpa por sua própria situação de excluído social (1998, p. 86-232).

A presença dos interesses do capital nos projetos financiados pelo Banco Mundial pode ser observada nos dois últimos projetos financiados pelo banco para o ensino fundamental público da Região Nordeste do país: o Projeto Nordeste para Educação Básica ${ }^{9}$ e o Fundo de Desenvolvimento da Escola (Fundescola).

O Projeto Nordeste para Educação Básica, ${ }^{10}$ implementado de 1994 a 1998 nos nove estados nordestinos, contava com mecanismos contratuais

9 Consultar a dissertação de Mestrado "Banco Mundial e Política Educacional: o Projeto Nordeste para Educação Básica e seus desdobramentos no Piauí", defendida por Rosana Evangelista da Cruz, em abril de 2002, no Programa de Pós-Graduação em Educação da Universidade de São Paulo.

10 O Projeto Nordeste para Educação Básica apresenta como objetivo melhorar a qualidade do ensino nas primeiras séries do ensino fundamental das redes estadual e municipais de educação, propondo a integração entre Estado e Municípios e a mudança no padrão de gestão da educação pública. Para viabilizar seus objetivos, o Projeto Nordeste organiza-se em diferentes Componentes Estratégicos: Gestão Educacional; Capacitação de Recursos Humanos; Materiais de Ensino-Aprendizagem e Rede Física e Inovações Pedagógicas. O financiamento das ações previstas no Projeto envolvia uma previsão inicial, em 1994, de US\$ 745.100.000,00 (setecentos e quarenta e cinco milhões e cem mil dólares). 
compatíveis com a expansão dos interesses do capital internacional, por meio de condicionalidades, a exemplo das Metas Anuais de Gerenciamento Eficiente, as quais exigiam a diminuição da proporção funcionário-aluno nos estados envolvidos, como pré-requisito para recebimento das parcelas mais significativas dos recursos, estimulando, assim, o enxugamento do aparelho de estado. Outro elemento central que denuncia o papel desses empréstimos é a exigência de que parte das compras dos equipamentos e materiais seja executada por meio de licitações internacionais, conforme critérios estabelecidos pelo banco em seu manual de operacionalização. Além do mais, o projeto instituiu um fundo competitivo, mecanismo para a distribuição dos recursos conforme a capacidade gerencial de cada estado envolvido, promovendo uma lógica típica do sistema capitalista: a competitividade entre os diferentes agentes envolvidos na execução da proposta.

O Fundescola dá continuidade às ações desenvolvidas pelo Projeto Nordeste e destina-se ao ensino fundamental das regiões Norte, Nordeste e Centro-Oeste, com execução prevista entre os anos de 1998 a 2003. ${ }^{11}$ Esse programa define que o atendimento aos municípios terá como critério a escolha das microrregiões com maior contingente demográfico, o que, por um lado, combate o uso de critérios políticos no processo de definição da distribuição dos recursos e, no entanto, por outro, reforça a idéia do Banco Mundial da educação como estratégia de contenção demográfica.

Dentre os principais aspectos que diferenciam o Projeto Nordeste do Fundescola, o repasse de recursos diretamente às unidades escolares, por meio de unidades executoras das escolas (conselhos escolares, associ-

11 O Fundescola envolve um montante de US\$ 1,3 bilhões, sendo de US\$ 650 milhões a contrapartida do governo federal e o restante do BIRD, em três empréstimos diferentes (Fundescola I, II e III). A maioria das ações previstas neste Programa dá continuidade àquelas desenvolvidas no Projeto Nordeste, pretensamente, com maior aprimoramento: Programa de Formação dos Professores em Exercício (Proformação), Programa de Gestão da Aprendizagem Escolar (formação continuada), Escola Ativa (salas multisseriadas), Atendimento Rural (construção de escolas em assentamentos, aldeias e áreas remanescentes de quilombos), Plano de Desenvolvimento da Escola (PDE), Projeto de Melhoria da Escola (PME), Definição dos Padrões Mínimo de Funcionamento das escolas, Projeto de Adequação do Prédio Escolar (Pape), Levantamento da Situação Escolar (LSE), Microplanejamento Educacional, Projeto Espaço Educativo (projeto arquitetônico para construir novas escolas), Desenvolvimento Institucional (capacitação de dirigentes educacionais e conselheiros do Fundef e assessorias), software para auxiliar na elaboração dos Planos de Carreira e informatização das coordenações do Fundescola. 
ação de pais e mestres, caixa escolar), se destaca. Os recursos do programa que vão diretamente para as unidades executoras são: Projeto de Adequação dos Prédios Escolares (Pape); Programa de Melhoria da Escola (PME) e o PDE (Plano de Desenvolvimento da Escola). ${ }^{12}$

A política de descentralização obriga as escolas a executarem ações até então sob a responsabilidade das secretarias de educação, como, por exemplo, o processo de licitação, compras e contratação de mão-de-obra para reformas. Esse procedimento envolve um volume considerável de recursos e uma complexidade adicional no processo de prestação de contas, visto as normas específicas do Banco Mundial.

A introdução dessa nova forma de administração escolar inseriu novos elementos na atuação cotidiana da direção escolar, uma vez que esta, além de tornar-se gestora de recursos, deve responsabilizar-se pelos orçamentos dos materiais e da mão-de-obra, pela compra e contratação de serviços, pela fiscalização das ações no âmbito da rede física da escola, da merenda, do material de consumo, dentre outros. Além disso, esse processo de descentralização não exime a direção escolar da responsabilidade com as demais ações regulares da escola como: controle de matrícula, administração de pessoal, integração com a comunidade, acompanhamento de ações educacionais da escola. O excesso de responsabilidade, sem a oferta de estrutura adequada para os gestores das escolas, exige a priorização de certas atividades, sendo que a parte burocrática para o funcionamento da instituição passa a ser priorizada, em detrimento de outras ações fundamentais para a garantia da execução do papel educativo da escola.

O Fundescola coloca a escola como centro de suas ações, na perspectiva de implementar as políticas de descentralização. Vários autores, a exemplo de ROSAR (1995) e GENTILI (1996), têm problematizado as políticas de descentralização, analisadas como mecanismo de desresponsabilização do governo federal e estadual com o financiamento da educação e o elemento de desconstrução do sistema educacional, de forma a deixá-lo permeável aos interesses privados no setor.

No que se refere aos aspectos legais e às orientações para os procedimentos, não ocorreram modificações substanciais em relação ao Projeto Nordeste, havendo, entretanto, maior dificuldade no uso dos recursos, como

12 As Unidades Executoras recebem, ainda, do Fundo Nacional de Desenvolvimento da Educação os recursos do Programa Dinheiro Direto na Escola (PDDE) e do Programa Nacional da Alimentação Escolar (PNAE). 
por exemplo, a compra de equipamentos escolares (carteiras, mesas, ventiladores, armários de aço) que, após a conclusão da licitação, devem ter amostras encaminhadas ao Instituto de Pesquisas Tecnológicas de São Paulo (IPT) para teste de qualidade e resistência antes da efetivação da compra. Esse procedimento, segundo levantamento realizado em 2001, burocratiza o processo, pois enquanto não for concluído, o Estado é obrigado a pagar a taxa de permanência dos recursos que estão parados sendo prejudicado financeiramente e, também, pela impossibilidade de pleno funcionamento das escolas.

A questão da incompatibilidade entre as orientações administrativas do Banco Mundial e as normas jurídicas nacionais ocasiona prejuízos visíveis aos cofres públicos, entretanto o próprio senado federal, baseado em parecer da Procuradoria Geral da União, determina que as normas externas, em relação ao empréstimo do Fundescola, devem prevalecer sobre as nacionais em caso de incompatibilidade. Este posicionamento demonstra que o país se curva às normas das agências internacionais com as quais estabelece relação de "cooperação".

Em suma, a análise da intervenção do Banco Mundial nas políticas educacionais brasileiras evidencia a expansão das políticas mais convenientes aos interesses do capital. Essas políticas contam com o apoio decisivo dos governos e das elites nacionais que viabilizam sua inserção e operacionalização, conforme as orientações das agências que monitoram, por meio do mecanismo das condicionalidades, as metas acertadas nos ditos acordos de cooperação internacional. Nesse sentido, a propalada "cooperação" consiste, de fato, em estratégia de expansão das políticas e interesses do capital internacional, sendo que a educação, nessa perspectiva, restringe-se ao papel de reproduzir a força de trabalho para o capital, formar ideologicamente conforme os interesses do mesmo e servir como segmento do mercado a ser explorado comercialmente pelo setor privado. 


\section{REFERÊNCIAS}

ARRUDA, M. Dívida E(x)terna: para o capital, tudo; para o social, migalhas. Petrópolis: Vozes, 1999.

ARRUDA, M. ONGs e o Banco Mundial: é possível colaborar criticamente? In: TOMMASI, L.; WARDE, M. J.; HADDAD, S. (Orgs.). O Banco Mundial e as políticas educacionais. 2. ed. São Paulo: Cortez, 1998. p. 41-74.

BANCO MUNDIAL. Prioridades y estratégias para la educación. Estudo Sectorial versión preliminar. Tradução de Rosana Evangelista da Cruz. Washington/DC: Banco Mundial, 1995. p. i-xxxii.

BANCO MUNDIAL. Relatório n. 16582BR. Memorando do presidente do Banco Internacional para Reconstrução e Desenvolvimento e da Cooperação Financeira Internacional aos diretores Executivos sobre a estratégia de assistência ao país do Grupo Banco Mundial para a República Federativa do Brasil. Washington/DC: Banco Mundial, jun. 1997.

BANCO MUNDIAL. Relatório sobre desenvolvimento mundial 1997: o Estado num mundo em transformação. Washington/DC: Banco Mundial, 1997. p. 1-39.

BANCO MUNDIAL. World Bank Brasil. Brasília: Banco Mundial, 1999. Mimeog.

BATISTA JÚNIOR, P. N. Mitos da “Globalização”. Rio de Janeiro: Camp, SindeconRJ, Fisenge, Pedex, Senge-RJ, 1998.

CASASSUS, J. Descentralização e desconcentração educacional na América Latina: fundamentos e crítica. Cadernos de Pesquisa, São Paulo, n. 74, p. 11-19, 1990.

CORAGGIO, J. L. Propostas do Banco Mundial para a Educação: sentido oculto ou problemas de concepção. In: TOMMASI, L.; WARDE, M. J.; HADDAD, S. (Orgs.). $O$ Banco Mundial e as políticas educacionais. 2. ed. São Paulo: Cortez, 1998. p. 75-124.

FONSECA, M. Apostila do minicurso "As reformas educativas no Brasil e as organizações Internacionais”. In: REUNIÃO ANUAL DA ANPED, 23., set. 2000, Caxambu/ MG. Mimeog.

FONSECA, M. O financiamento do Banco Mundial e a educação brasileira: 20 anos de cooperação internacional. In: TOMMASI, L.; WARDE, M. J.; HADDAD, S. (Orgs.). $O$ Banco Mundial e as políticas educacionais. 2. ed. São Paulo: Cortez, 1998. p. 229-253.

FRIGOTTO, G. A formação e profissionalização do educador: novos desafios. In: SILVA, T. T.; GENTILI, P. Escola S.A. - quem ganha e quem perde no mercado educacional do Neoliberalismo. Brasília: CNTE, 1996a. p. 75-105.

FRIGOTTO, G. Educação e a crise do capitalismo real. São Paulo: Cortez, 1996b. 
CRUZ, R. E. Banco Mundial e política educacional: cooperação ou expansão...

GENTILI, P. Neoliberalismo e educação: manual do usuário. In: SILVA, T. T.; GENTILI, P. Escola S.A. - quem ganha e quem perde no mercado educacional do Neoliberalismo. Brasília: CNTE, 1996. p. 9-49.

HAYEK, F. A. O caminho da servidão. Rio de Janeiro: Biblioteca do Exército, 1994.

KRUPPA, S. M. P. O Banco Mundial e as Políticas Públicas de Educação nos anos 90. São Paulo: FEUSP, 2000. Tese (Doutorado em Educação) - USP.

LEHER, R. Da ideologia do desenvolvimento à ideologia da globalização: a educação como estratégia do Banco Mundial para “alívio” da pobreza. São Paulo: FEUSP, 1998. Tese (Doutorado em Educação) - USP.

LICHTENSZTEJN, S.; BAUER, M. Fundo Monetário Internacional e Banco Mundial - Estratégias e políticas do poder financeiro. São Paulo: Brasiliense, 1987.

NEGRÃO, J. J. O. O governo FHC e o neoliberalismo. Lutas Sociais, São Paulo: Neils/ Xamã, n. 1., p. 103-111, 1996.

NOGUEIRA, F. M. G. Ajuda Externa para a Educação Brasileira - Da USAID ao Banco Mundial. Cascavel/PR: Unioeste, 1999.

OLIVEIRA, F. O surgimento do antivalor - capital, força de trabalho e Fundo público. In: OLIVEIRA, F. Os direitos do Antivalor. Petrópolis: Vozes, 1998. p. 19-48.

PERONI, V. M. V. A redefinição do papel do Estado e a política educacional no Brasil nos anos 90. São Paulo, 1999, p. 23-157. Tese (Doutorado em História e Filosofia da Educação) - PUC-SP.

ROSAR, M. F. F. Globalização e descentralização: o processo de desconstrução do Sistema Educacional Brasileiro pela via da municipalização. Campinas, 1995. Tese (Doutorado em Educação) - Unicamp.

SANTOS, M. A grande crise se instalou. In: BENJAMIN, C.; ELIAS, L. Brasil: crise e destino. Entrevista com pensadores contemporâneos. São Paulo: Expressão Popular, 2000. p. 21-34.

SILVA, M. A. Políticas para a educação pública: intervenção das instituições financeiras internacionais e o consentimento nacional. Campinas, 1999. Tese (Doutorado em Educação) - Unicamp.

SOARES, M. C. C. Banco Mundial: políticas e reformas. In: TOMMASI, L.; WARDE, M. J.; HADDAD, S. (Orgs.). O Banco Mundial e as políticas educacionais. 2. ed. São Paulo: Cortez, 1998. p. 15-40.

TORRES, R. M. Melhorar a qualidade da Educação Básica: Estratégias do Banco Mundial. In: TOMMASI, L.; WARDE, M. J.; HADDAD, S. (Orgs.). O Banco Mundial e as políticas educacionais. 2. ed. São Paulo: Cortez, 1998. p. 125-194. 
VIANNA JUNIOR., A. (Org.). A estratégia dos Bancos Multilaterais para o Brasil: uma análise crítica de documentos inéditos. Brasília: Rede Brasil, 1998.

VIANNA JUNIOR., A. O Banco Internacional para Reconstrução e Desenvolvimento (Bird) - Banco Mundial In: CENTRAL ÚNICA DOS TRABALHADORES. Guia Resumido das Organizações Internacionais. São Paulo: CUT/CFDT/INESC/FASE, 1999. p. $42-55$.

VIANNA JUNIOR, A. O Painel de Inspeção do Banco Mundial, um instrumento para a participação. In: LEROY, J. P.; SOARES, M. C. C. Bancos Multilaterais e Desenvolvimento Participativo no Brasil: dilemas e desafios. Rio de Janeiro: Fase-Ibase, 1998. p. 191-210.

VIANNA JUNIOR, A. Pronunciamento na Câmara dos Deputados. In: BRASIL. Câmara dos Deputados. Comissão de Fiscalização Financeira e Controle. Audiência Pública: Os financiamentos das Instituições Financeiras Multilaterais e o orçamento da União. Brasília/DF: Câmara dos Deputados, 11 ago. 1998.

VIANNA JUNIOR., A.; PARECHI, A. C. La participación de la sociedad civil en los programas del Banco Mundial y del BID: El caso de Brasil. Argentina: Flacso/Rede Brasil, 1999. (Serie de documentos e informes de Investigación).

Texto recebido em 10 ago. 2003

Texto aprovado em 03 out. 2003 